\title{
Diabetes Mellitus Does Not Affect Jugular Bulb Oxygen Saturation in Patients Undergoing Off-Pump Coronary Artery Bypass Graft Surgery
}

\author{
Young Jun Oh, MD, $\mathrm{PhD}^{*, * *}$; Ji Young Kim, MD, $\mathrm{PhD}^{\dagger}$; Jae Kwang Shim, MD*,**; \\ Kyung Jong Yoo, $\mathrm{MD}, \mathrm{PhD}^{\dagger}$; Jong Wha Lee, MD, $\mathrm{PhD} * * *$; Young Lan Kwak, MD, $\mathrm{PhD} * * * *$
}

\begin{abstract}
Background Diabetes mellitus (DM) is associated with the impairment of cerebral oxygenation during cardiac surgery. The aim of the present study was to investigate the effects of DM on cerebral oxygenation assessed by jugular bulb oxygen saturation $\left(\mathrm{SjvO}_{2}\right)$ in patients undergoing off-pump coronary artery bypass graft surgery (OPCAB) in a prospective controlled trial.

Methods and Results Twenty-three diabetic patients with glycosylated hemoglobin above $7.0 \%$ (DM group) and 23 non-diabetic patients (control group) undergoing OPCAB with no-touch aortic technique were included. A fiberoptic oximetry catheter was inserted into the jugular bulb. The lowest $\mathrm{SjvO}_{2}$ and the number of patients with cerebral desaturation, defined as $\mathrm{SjvO}_{2}$ less than $50 \%$ over $5 \mathrm{~min}$, were recorded during coronary grafting. Three neurocognitive tests were done before surgery and at postoperative day 2 and 7 . There were no differences in $\mathrm{SjvO}_{2}$ between the groups. Furthermore, the number of patients with cerebral desaturation and all neurocognitive test scores were similar between the 2 groups. None of the patients developed neurocognitive dysfunction. Conclusions Cerebral oxygenation in diabetic patients was similar to that of non-diabetic patients and well maintained above the critical level without resulting in clinically significant postoperative neurocognitive dysfunction during OPCAB with no-touch aortic technique. (Circ J 2008; 72: 1259-1264)
\end{abstract}

Key Words: Coronary artery bypass surgery; Diabetes mellitus; Jugular bulb oxygen saturation; Off-pump

D espite advances in surgical and anesthetic techniques over the years, cardiac surgery continues to be associated with considerable incidences of postoperative neurological deficits! These deficits vary from permanent defects, such as stroke, to transient conditions, such as intellectual dysfunction, confusion and/or memory deficits, which are reported in over $50 \%$ of patients in the early postoperative period?2,3 Diabetes mellitus (DM) itself is not only an established risk factor for the development of coronary artery occlusive disease (CAOD), but also one of the major factors related to adverse postoperative neurological disorders after coronary artery bypass graft surgery $(\mathrm{CABG})^{4,5}$ Frequent development of postoperative neurological deficits in patients with DM has been thought to be associated with the impairment of cerebral perfusion and autoregulation following cardiac surgery under cardiopulmonary bypass $(\mathrm{CPB}), 7$

Jugular bulb oxygen saturation $\left(\mathrm{SjvO}_{2}\right)$ is a useful indica-

(Received November 18, 2007; revised manuscript received February 21, 2008; accepted March 14, 2008)

*Department of Anesthesiology and Pain Medicine, **Anesthesia and Pain Research Institute, Yonsei University College of Medicine, Seoul, 'Department of Anesthesiology and Pain Medicine, Gachon Medical School, Gil Medical Center, Incheon and Hepartment of Thoracic and Cardiovascular Surgery, Yonsei University College of Medicine, Seoul, Republic of Korea

Mailing address: Young Lan Kwak, MD, PhD, Department of Anesthesiology and Pain Medicine, Anesthesia and Pain Research Institute, Yonsei University College of Medicine, 134 Shinchon-dong, Seodaemun-ku, Seoul 120-752, Republic of Korea. E-mail: ylkwak @yuhs.ac

All rights are reserved to the Japanese Circulation Society. For permissions, please e-mail: cj@j-circ.or.jp tor of global cerebral blood flow provided that the cerebral metabolic rate is constant, and it also aids estimating cerebrovascular reserve by measuring the cerebrovascular $\mathrm{CO}_{2}$ reactivity $\left(\mathrm{CVR}-\mathrm{CO}_{2}\right)^{8,9}$ Kadoi et al reported that reduced $\mathrm{SjvO}_{2}$ during $\mathrm{CPB}$ was associated with short-term postoperative cognitive deficit $1^{1} \mathrm{Also}$, in a series of studies, diabetic patients more frequently exhibited reduced $\mathrm{SjvO}_{2}$ during CPB when compared with patients without DM, $60-12$

Over the past decade, off-pump CABG (OPCAB) has become popular and showed favorable cerebral outcomes because it can avoid the use of $\mathrm{CPB}$, which gives rise to cerebral hypoperfusion and microemboli!13,14 Some investigators showed that $\mathrm{OPCAB}$ could provide well preserved global cerebral oxygenation despite significant hemodynamic changes during target vessel anastomosis. ${ }^{15}$ However, no studies have been done to confirm whether cerebral oxygenation can be maintained in patients with DM during $\mathrm{OPCAB}$. The aim of the current study was to investigate the effects of DM on cerebral oxygenation assessed by $\mathrm{SjvO}_{2}$ and subsequently on early postoperative neurocognitive function in patients undergoing $\mathrm{OPCAB}$ in a prospective, controlled trial.

\section{Methods}

\section{Patients and Anesthetic Management}

The present study was approved by the ethics committee of our institution and written informed consent was obtained from all patients. A total of 23 patients with DM scheduled for elective OPCAB were included (DM group). The DM group was defined as those whose medical records showed a diagnosis of type $2 \mathrm{DM}$ who had been treated with oral 
hypoglycemic agents or insulin therapy and also had glycosylated hemoglobin (HbAlc) concentration above 7.0\%. Twenty-three patients without DM undergoing elective OPCAB matched for age, weight, height, sex, severity of CAOD, left ventricular ejection fraction and educational level were also included (control group). Patients with a history of stroke, neurological or psychiatric illness, renal disease, active liver disease, congestive heart failure, peripheral artery obstructive disease, and carotid artery stenosis over $60 \%$ narrowing by carotid duplex ultrasonography scans were excluded. Patients who needed aortic sideclamping for proximal anastomosis of coronary artery were also excluded to rule out the possibility of cerebral emboli by this maneuver.

On the day of surgery, all patients were premedicated with intramuscular injection of morphine $0.05 \mathrm{mg} / \mathrm{kg}$. In the operating room, standard monitoring devices were applied including a pulmonary arterial catheter (Swan-Ganz CCOmbo $\mathrm{CCO} / \mathrm{SvO} 2$, Edwards Lifesciences LLC, Irvine, CA, USA), which was inserted through the right internal jugular vein before induction of anesthesia. This was connected to an analysis system (Vigilance, Edwards Lifesciences LLC, CA, USA) for continuous monitoring of cardiac index (CI) and mixed venous oxygen saturation $\left(\mathrm{SvO}_{2}\right)$.

Anesthesia was induced with midazolam $0.05 \mathrm{mg} / \mathrm{kg}$, sufentanil $1.5-3.9 \mu \mathrm{g} / \mathrm{kg}$, and rocuronium bromide $0.9 \mathrm{mg} / \mathrm{kg}$ was administered to facilitate endotracheal intubation. Anesthesia was maintained with continuous infusion of sufentanil $\left(0.5-1.5 \mu \mathrm{g} \cdot \mathrm{kg}^{-1} \cdot \mathrm{h}^{-1}\right)$, vecuronium bromide $(1.0-2.0 \mu \mathrm{g}$. $\mathrm{kg}^{-1} \cdot \mathrm{min}^{-1}$ ) and isoflurane (less than $1.0 \%$ ) in 50\% oxygen with air.

The depth of anesthesia was monitored with bispectral index score (BIS) monitor (A-2000, Aspect Medical System Inc, Newton, MA, USA) and BIS was maintained between 40 and 60.

After induction of anesthesia, the transesophageal echocardiography probe was inserted to detect newly developing segmental wall motion abnormalities. Intravascular volume replacement was managed with crystalloid and colloid solutions to maintain the pulmonary capillary wedge pressure between 8 and $14 \mathrm{mmHg}$ according to the baseline values before the displacement of the heart. Central temperature measured by pulmonary artery catheter was maintained between 36.0 and $37.0^{\circ} \mathrm{C}$ with warm mattress, forced warm air blanket and fluid warmer as necessary. Allogenic packed red blood cells were transfused when the hematocrit concentration was $<25 \%$ for patients $\geq 65$ years of age and when the hematocrit concentration was $<23 \%$ for patients $<65$ years of age throughout the study period. Isosorbide dinitrate $\left(0.5 \mu \mathrm{g} \cdot \mathrm{kg}^{-1} \cdot \mathrm{min}^{-1}\right)$ was infused in all patients and blood glucose concentration was maintained between 80 and $150 \mathrm{mg} / \mathrm{dl}$ with intravenous insulin administration as necessary.

All surgical procedures were carried out by one surgeon through a median sternotomy and the heart was displaced using posterior pericardial stitch, large $(12 \times 70 \mathrm{~cm})$ gauze swabs and tissue stabilizer (Octopus Tissue Stabilization System, Medtronic Inc, Minneapolis, MN, USA). During the period of heart displacement, mean systemic arterial pressure (MAP) was maintained above $70 \mathrm{mmHg}$ either with 10 $20^{\circ}$ Trendelenburg position and/or norepinephrine infusion.

\section{Measurement of $\mathrm{CVR}-\mathrm{CO}_{2}$}

For continuous monitoring of the $\mathrm{SjvO}_{2}, 4.0 \mathrm{~F}$ fiberoptic oximetry catheter (Dual-Lumen Oximetry catheter, Edwards
Lifesciences LLC, CA, USA) was inserted into the left internal jugular vein in the cephalad direction via the modified Seldinger technique until resistance was sensed at the jugular bulb. The catheter was withdrawn approximately $3-5 \mathrm{~mm}$ from the resistant position. The positioning of the jugular bulb catheter tip was verified by radiograph. The correctly positioned catheter tip should lie cranial to a line extending from the atlanto-occipital joint space and caudal to the lower margin of the orbit. This catheter was connected to another analysis system (Vigilance) and calibrated in vivo by drawing a blood sample from the catheter. $\mathrm{SjvO}_{2}$ values were collected and processed in a computer monitor interface, and were displayed every $5 \mathrm{~s}$. Cerebral desaturation was defined as $\mathrm{SjvO}_{2}$ less than $50 \%$ over $5 \mathrm{~min}$.

During harvesting of the internal mammary artery, ventilation was adjusted to maintain $\mathrm{PaCO}_{2} 45 \pm 2 \mathrm{mmHg}$ (time $\mathrm{T} 1$ ) for $10 \mathrm{~min}$ and the $\mathrm{SjvO}_{2}$ value was recorded. Thereafter, hyperventilation was induced until $\mathrm{PaCO}_{2}$ was reduced to $35 \pm 2 \mathrm{mmHg}$ and maintained for $10 \mathrm{~min}$ before recording $\mathrm{SjvO}_{2}$ value (time $\left.\mathrm{T}_{2}\right)$. The changes of $\mathrm{SjvO}_{2}\left(\Delta \mathrm{SjvO}_{2}\right)$ and that of $\mathrm{PaCO}_{2}\left(\triangle \mathrm{PaCO}_{2}\right)$ were measured between time $\mathrm{T}_{1}$ and $\mathrm{T}_{2}$. The CVR-CO2, expressed as the percentage change in $\mathrm{SjvO}_{2}$ per a $1 \mathrm{mmHg}$ change in $\mathrm{PaCO}_{2}\left(\Delta \mathrm{SjvO}_{2} / \Delta \mathrm{PaCO}_{2}\right)$, was calculated. After then, ventilation was controlled to maintain $\mathrm{PaCO}_{2} 35 \pm 2 \mathrm{mmHg}$ throughout the surgery.

\section{Measurements of Physiologic Variables}

Physiologic variables including MAP, heart rate, mean pulmonary artery pressure, central venous pressure (CVP), $\mathrm{CI}, \mathrm{SvO}_{2}$ and $\mathrm{SjvO}_{2}$ were recorded just before the manipulation of the heart (baseline), at 10 min after the application of the tissue stabilizer on the left anterior descending coronary artery, left circumflex coronary artery (LCX) and right coronary artery (RCA) and at skin closure. In addition, the value of the lowest $\mathrm{SjvO}_{2}$ and the number of patients with $\mathrm{SjvO}_{2}$ below $50 \%$ for $1-5 \mathrm{~min}$ and over $5 \mathrm{~min}$ during each coronary arterial anastomosis were recorded. Hematocrit concentration was assessed at each time point of measurement.

\section{Measurements of Neurocognitive Function}

All patients underwent a set of neurocognitive tests the day before operation and postoperative day (POD) 2 and 7 . The examiner who administered the cognitive tests was unaware of whether patients were in the DM or control group. Neurocognitive function was tested with Mini-Mental State Examination (MMSE), Trail-Making Test (Part A) and Grooved Pegboard Test. MMSE tests the neurocognitive function such as orientation, registration, attention and calculation, recall and language. Trail-Making Test (Part A) and Grooved Pegboard Test examine complex visuo-motor coordination. To obtain an indicator of outcome, overall significant impairment was defined as a decline from preoperative testing of more than $20 \%$ reduction at least 1 of 3 test measures. Major neurologic defects (defined as clinical evidence of focal cerebral infarction including hemiparesis, visual or gait disturbance; mental changes such as confusion, agitation, inability to make contact with other people) were also evaluated after surgery.

\section{Statistical Analysis}

The sample size calculation was based on the previous similar study 12 that the $\mathrm{SjvO}_{2}$ value in diabetic patients would be decreased by $10 \%$ compared with that in control patients with standard deviation of $10 \%$ during coronary 
artery grafting. For an alpha error of 0.05 and power of $90 \%$, a total of 23 patients per group were found to be necessary.

Data were analyzed with SPSS (version 12.0, SPSS Inc, Chicago, IL, USA) and expressed as mean \pm standard deviation or number of patients. $\mathrm{X}^{2}$-test or Fisher's exact test was performed to compare the patient characteristics and the number of patients with $\mathrm{SjvO}_{2}$ below $50 \%$ between the groups. Unpaired t-test was used to compare the difference in $\mathrm{SjvO}_{2}$ and hemodynamic variables between the 2 groups. Repeated measures of analysis of variance was used to compare the difference in hemodynamic variables and $\mathrm{SjvO}_{2}$ within each group. A p-value of less than 0.05 was considered statistically significant.

\section{Results}

Patients' characteristics and operative data are summarized in Table 1 . There were no significant differences in demographic data except $\mathrm{HbA} 1 \mathrm{c}$ and fasting blood sugar. Mean duration of DM was $12.0 \pm 7.7$ years, and 4 patients were treated with insulin and remaining patients were treated with oral hypoglycemic agents in the DM group. The CVR-CO 2 was similar between the 2 groups (Table 2).

Hemodynamic variables, hematocrit concentration and $\mathrm{SjvO}_{2}$ of baseline and 10 min after the application of the tissue stabilizer during each coronary artery anastomosis are listed in Table 3. Although $\mathrm{CI}, \mathrm{SvO}_{2}$ and MAP significantly decreased compared to baseline values during LCX and RCA anastomoses in both groups, there were no significant differences between the groups. $\mathrm{SjvO}_{2}$ significantly decreased compared to baseline values during LCX anastomosis in the control group and during RCA anastomosis in the DM group without significant difference between the groups. Hematocrit concentration was also decreased during the surgery compared to baseline values in both groups without significant intergroup differences. The total amount of infused norepinephrine during the surgery was larger in the DM group without statistical significance $(119 \pm 151 \mu \mathrm{g}$
Table 1 Patients Characteristics and Operative Data

\begin{tabular}{lcc}
\hline \hline & $\begin{array}{c}\text { Control group } \\
(n=23)\end{array}$ & $\begin{array}{c}\text { DM group } \\
(n=23)\end{array}$ \\
\hline HbAlc $(\%)$ & $5.3 \pm 0.4$ & $8.2 \pm 0.5^{*}$ \\
Fasting blood sugar $(\mathrm{mg} / \mathrm{dl})$ & $107 \pm 16$ & $161 \pm 41^{*}$ \\
Grafted coronary arteries $(n)$ & $3.6 \pm 0.4$ & $3.4 \pm 0.5$ \\
Sex $(M / F)$ & $19 / 4$ & $17 / 6$ \\
Age $($ years $)$ & $63 \pm 5$ & $63 \pm 6$ \\
Body surface area $\left(\mathrm{m}^{2}\right)$ & $1.72 \pm 0.14$ & $1.72 \pm 0.16$ \\
Left ventricular ejection fraction $(\%)$ & $62 \pm 8$ & $59 \pm 13$ \\
Hypertension $(n)$ & 17 & 15 \\
Smoking $(n)$ & 10 & 9 \\
Educational level $($ years of studying) & $13.2 \pm 3.1$ & $12.9 \pm 2.8$ \\
Cardiac medication $(n)$ & & \\
$\quad K^{+}$channel opener & 19 & 18 \\
Ca ${ }^{2+}$ channel blocker & 6 & 8 \\
$R A S$ antagonist & 12 & 14 \\
$\beta$-blocker & 20 & 19 \\
\hline
\end{tabular}

Data are mean $\pm S D$ or number of patients.

$D M$, patients with diabetes mellitus; HbAlc, glycosylated hemoglobin; RAS, renin angiotensin system.

${ }^{*} p<0.001$ vs control group.

Table 2 Cerebrovascular $\mathrm{CO}_{2}$ Reactivity Before Coronary Arterial Anastomosis

\begin{tabular}{lccc}
\hline \hline & Group & $T_{1}$ & $T_{2}$ \\
\hline $\mathrm{PaCO}_{2}(\mathrm{mmHg})$ & Control & $43.8 \pm 1.0$ & $34.8 \pm 1.1^{*}$ \\
$\mathrm{SjvO}_{2}(\%)$ & DM & $45.0 \pm 1.7$ & $34.9 \pm 1.2^{*}$ \\
& Control & $75.4 \pm 5.6$ & $62.0 \pm 6.7^{*}$ \\
$\mathrm{SSjO}_{2} / \mathrm{\triangle PaCO}(\% / \mathrm{mmHg})$ & Control & $78.0 \pm 6.6$ & $63.1 \pm 9.2^{*}$ \\
& $D M$ & \multicolumn{2}{c}{$1.5 \pm 0.5$} \\
& & \multicolumn{2}{c}{$1.5 \pm 0.6$}
\end{tabular}

Data are mean $\pm S D$.

$\mathrm{T}_{1}$, target $\mathrm{PaCO}_{2} 45 \pm 2 \mathrm{mmHg} ; \mathrm{T}$, target $\mathrm{PaCO}_{2} 35 \pm 2 \mathrm{mmHg}$; $\mathrm{SjO}_{2}$, jugular bulb oxygen saturation; $\Delta, T_{2}-T_{1}$. Other abbreviation see in Table 1. $*_{p}<0.001$ vs $T_{1}$

Table $3 \quad \mathrm{SjvO}_{2}$ and Hemodynamic Variables

\begin{tabular}{|c|c|c|c|c|c|c|}
\hline & Group & Baseline & $L A D$ & $L C X$ & $R C A$ & Skin closure \\
\hline \multirow{2}{*}{$\mathrm{PaCO}_{2}(\mathrm{mmHg})$} & Control & $35.1 \pm 0.8$ & $34.5 \pm 1.3$ & $34.8 \pm 0.9$ & $35.2 \pm 1.0$ & $34.7 \pm 1.2$ \\
\hline & $D M$ & $34.7 \pm 1.1$ & $34.9 \pm 0.9$ & $35.2 \pm 1.2$ & $35.0 \pm 0.8$ & $34.9 \pm 1.0$ \\
\hline \multirow[t]{2}{*}{$B I S$} & Control & $52 \pm 9$ & $47 \pm 8$ & $55 \pm 7$ & $49 \pm 8$ & $55 \pm 9$ \\
\hline & $D M$ & $54 \pm 6$ & $52 \pm 8$ & $51 \pm 10$ & $49 \pm 7$ & $52 \pm 10$ \\
\hline \multirow[t]{2}{*}{$C I\left(L \cdot \mathrm{min}^{-1} \cdot \mathrm{m}^{-2}\right)$} & Control & $2.5 \pm 0.4$ & $2.5 \pm 0.5$ & $2.0 \pm 0.5 *$ & $2.2 \pm 0.5 *$ & $2.4 \pm 0.6$ \\
\hline & $D M$ & $2.7 \pm 0.4$ & $2.6 \pm 0.4$ & $2.0 \pm 0.5 *$ & $2.3 \pm 0.7 *$ & $2.6 \pm 0.8$ \\
\hline \multirow[t]{2}{*}{$M A P(m m H g)$} & Control & $82 \pm 10$ & $79 \pm 5$ & $77 \pm 6^{*}$ & $75 \pm 7 *$ & $84 \pm 9$ \\
\hline & $D M$ & $80 \pm 12$ & $77 \pm 6$ & $75 \pm 6$ & $72 \pm 5 *$ & $85 \pm 10$ \\
\hline \multirow[t]{2}{*}{ HR (beats/min) } & Control & $59 \pm 10$ & $63 \pm 9$ & $67 \pm 10^{*}$ & $64 \pm 9 *$ & $69 \pm 12$ \\
\hline & $D M$ & $60 \pm 7$ & $64 \pm 7 *$ & $66 \pm 13 *$ & $69 \pm 10 *$ & $71 \pm 11$ \\
\hline \multirow[t]{2}{*}{$M P A P(m m H g)$} & Control & $18.4 \pm 2.7$ & $18.9 \pm 2.9$ & $20.2 \pm 3.9$ & $23.0 \pm 4.2 *$ & $16.4 \pm 4.3$ \\
\hline & $D M$ & $17.8 \pm 4.0$ & $20.0 \pm 4.9$ & $21.3 \pm 6.6$ & $21.9 \pm 5.5^{*}$ & $17.7 \pm 5.2$ \\
\hline \multirow[t]{2}{*}{$C V P(m m H g)$} & Control & $10.5 \pm 3.6$ & $10.0 \pm 1.4$ & $11.6 \pm 2.1$ & $14.1 \pm 3.3 *$ & $9.7 \pm 3.4$ \\
\hline & $D M$ & $9.6 \pm 4.0$ & $10.7 \pm 2.8$ & $11.1 \pm 4.5$ & $13.4 \pm 4.3 *$ & $10.2 \pm 3.0$ \\
\hline \multirow[t]{2}{*}{ Hematocrit (\%) } & Control & $32.0 \pm 4.8$ & $30.2 \pm 4.4^{*}$ & $29.5 \pm 4.7 *$ & $28.8 \pm 4.1 *$ & $26.7 \pm 3.9 *$ \\
\hline & $D M$ & $31.1 \pm 5.1$ & $29.7 \pm 5.1 *$ & $28.6 \pm 4.9 *$ & $27.6 \pm 3.9 *$ & $27.0 \pm 4.5^{*}$ \\
\hline \multirow[t]{2}{*}{$\mathrm{SvO}_{2}(\%)$} & Control & $82 \pm 5$ & $74 \pm 8^{*}$ & $67 \pm 10^{*}$ & $68 \pm 10^{*}$ & $83 \pm 6$ \\
\hline & $D M$ & $80 \pm 5$ & $71 \pm 7 *$ & $63 \pm 7 *$ & $63 \pm 7 *$ & $84 \pm 9$ \\
\hline \multirow[t]{2}{*}{$\mathrm{SjvO}_{2}(\%)$} & Control & $62 \pm 6$ & $60 \pm 6$ & $56 \pm 9 *$ & $57 \pm 6$ & $63 \pm 7$ \\
\hline & $D M$ & $63 \pm 7$ & $62 \pm 5$ & $59 \pm 7$ & $56 \pm 7 *$ & $65 \pm 8$ \\
\hline
\end{tabular}

Data are mean $\pm S D$.

$L A D$, left anterior descending coronary artery; LCX, left circumflex coronary artery; RCA, right coronary artery; BIS, bispectral index score; CI, cardiac index; MAP, mean arterial pressure; HR, heart rate; MPAP, mean pulmonary arterial pressure; CVP, central venous pressure; $\mathrm{SvO}_{2}$, mixed venous oxygen saturation. Other abbreviations see in Tables 1,2.

${ }^{*} p<0.05$ vs baseline. 
Table $4 \mathrm{SjvO}_{2}$ During Coronary Arterial Anastomosis

\begin{tabular}{|c|c|c|c|c|}
\hline & & $L A D$ & $L C X$ & $R C A$ \\
\hline \multirow[t]{2}{*}{ Anastomosis time (min) } & Control & $14.7 \pm 2.8$ & $16.1 \pm 4.2$ & $17.9 \pm 5.3$ \\
\hline & $D M$ & $15.6 \pm 5.4$ & $15.4 \pm 4.8$ & $16.5 \pm 5.4$ \\
\hline \multirow[t]{2}{*}{ Lowest $\mathrm{SjvO}_{2}(\%)$} & Control & $58 \pm 6$ & $56 \pm 7$ & $57 \pm 6$ \\
\hline & $D M$ & $58 \pm 5$ & $55 \pm 5$ & $56 \pm 7$ \\
\hline \multirow[t]{2}{*}{$\mathrm{SjvO}_{2}<50 \%$ for $1-5 \mathrm{~min}^{*}$} & Control & 0 & 0 & 0 \\
\hline & $D M$ & 0 & 2 & 2 \\
\hline \multirow[t]{2}{*}{$\mathrm{SjvO}_{2}<50 \%$ for longer than $5 \mathrm{~min}^{*}$} & Control & 0 & 2 & 1 \\
\hline & $D M$ & 0 & 2 & 1 \\
\hline
\end{tabular}

Data are mean $\pm S D$ or number of patients.

Abbreviations see in Tables 1-3.

*Number of patients.

Table 5 Neurocognitive Test Score at Perioperative Periods

\begin{tabular}{lcccc}
\hline \hline Tests & & Baseline & POD 2 & POD 7 \\
\hline \multirow{2}{*}{ MMSE } & Control & $28.0 \pm 1.4$ & $27.5 \pm 2.1$ & $28.3 \pm 1.5$ \\
& DM & $27.0 \pm 2.1$ & $26.3 \pm 2.6$ & $27.3 \pm 2.2$ \\
TMT-A $(s)$ & Control & $52.5 \pm 17.3$ & $56.4 \pm 26.0$ & $55.5 \pm 21.4$ \\
& $D M$ & $55.7 \pm 16.9$ & $56.4 \pm 21.3$ & $55.9 \pm 21.5$ \\
GP $(s)$ & Control & $85.2 \pm 18.6$ & $91.5 \pm 21.8^{*}$ & $87.0 \pm 17.3$ \\
& DM & $86.5 \pm 15.7$ & $91.6 \pm 15.1^{*}$ & $88.9 \pm 17.8$ \\
\hline
\end{tabular}

Data are mean $\pm S D$.

Baseline, 1 day before surgery; POD, postoperative day; MMSE, mini-mental state examination; TMA-A, trail-making test (part-A); GP, grooved pegboard. Other abbreviation see in Table 1.

$* p<0.05$ vs baseline.

and $220 \pm 224 \mu \mathrm{g}$ in the control and DM group, respectively, $\mathrm{p}=0.08)$.

The duration of each coronary artery anastomosis, the lowest $\mathrm{SjvO}_{2}$ value, and the number of patients with $\mathrm{SjvO}_{2}$ less than $50 \%$ for $1-5 \mathrm{~min}$ and over $5 \mathrm{~min}$ during each coronary artery anastomosis were not different between the 2 groups (Table 4).

None of the patients developed major neurological deficits postoperatively. All neurocognitive test scores were comparable between the groups before and after surgery. Scores in MMSE and Trail-Making test did not significantly change after surgery compared to baseline scores in both groups. The time taken to complete Grooved Pegboard Test was significantly increased at POD 2 in both groups compared to baseline values, which returned to the baseline value at POD 7. It was prolonged more than $20 \%$ of the baseline in 4 and 6 patients in the control and DM group, respectively at $\mathrm{POD} 2$, but returned to baseline level in all patients at POD 7 (Table 5).

\section{Discussion}

In this prospective trial we could observe that the balance between cerebral blood flow and metabolic rate could be well maintained in diabetic patients to a similar degree as in non-diabetic patients during OPCAB. These observations were irrespective of an accompanying decrease in CI and $\mathrm{SvO}_{2}$ during grafting while $\mathrm{PaCO}_{2}$ and MAP were kept constant within the normal range. Accordingly, none of the patients developed early postoperative neurocognitive dysfunction.

Diabetic patients represent an important subgroup population who undergo cardiac surgery, and compared with nondiabetic patients, they have a variety of increased morbid events, including neurologic complications ${ }^{16,17}$ One of the possible causes of increased postoperative neurologic defi- cits in diabetic patients is impaired cerebrovascular circulatory and vasodilatory reserve ${ }^{18,19}$ Hyperglycemia leads to impaired vascular function by altering endothelial cell function. The pathway that appears most affected by DM is that of nitric oxide ${ }^{20}$ and CPB might alter the cerebral endothelial function more extensively in diabetic patients than in non-diabetic patients. ${ }^{12}$ As a result, diabetic patients lose the normal coupling of cerebral blood flow with metabolism during CPB and usual cerebral blood flow-perfusion pressure relationship? CVR- $\mathrm{CO}_{2}$ has significant correlation with cerebral autoregulatory index and diabetic patients with reduced $\mathrm{CVR}-\mathrm{CO}_{2}$ were reported to have a tendency to have a cerebral desaturation state ${ }^{21}$ As a result of such impairment of cerebrovascular function, in a series of studies observing cerebral oxygenation with $\mathrm{SjvO}_{2}$, diabetic patients more often experienced cerebral desaturation $\left(<\mathrm{SjvO}_{2} 50 \%\right)$ than non-diabetic patients during CPB?,12 Cerebral desaturation during $\mathrm{CPB}$ is also reported to be closely related to postoperative neurological disorder ${ }^{22}$ Considering that impaired cerebrovascular function in diabetic patients are mostly related to $\mathrm{CPB}$ and use of $\mathrm{CPB}$ is the only predictor of short-term cognitive dysfunction after $\mathrm{CABG}_{2}^{23} \mathrm{OPCAB}$ could exert beneficial effect in terms of cerebral oxygenation in patients with DM. However, there are no prospective, controlled trials to support this hypothesis by far.

As our results indicate, $\mathrm{CVR}-\mathrm{CO}_{2}$ representing cerebral autoregulatory index and $\mathrm{SjvO}_{2}$ were all well maintained in diabetic patients to a similar degree as in non-diabetic patients during OPCAB. Furthermore, there were no differences in $\mathrm{SjvO}_{2}$ and frequency of cerebral desaturation between diabetic and non-diabetic patients during grafting when $\mathrm{CI}$ and $\mathrm{SvO}_{2}$ were significantly decreased as a consequence of mechanical displacement of the heart and temporary coronary hemostasis. This can be explained by the fact that many cardiovascular risk factors are present long before the development of diabetes has led to increasing support 
for the 'common ground' hypothesis in which type 2 diabetes, and cardiovascular disease share common genetic and environmental antecedents. ${ }^{24}$ Therefore, DM itself can be considered as not a factor affecting the cerebrovascular reserve in patients with CAOD, but rather be a co-factor augmenting the effect of a trigger factor, which damages vascular reactivity, such as $\mathrm{CPB}$. The result of the current study could be a possible explanation for the previous report that OPCAB in diabetic patients significantly decreased the incidence of postoperative neurologic complication when compared with $\mathrm{CABG}$ under $\mathrm{CPB} 25$

Estimation of cerebral oxygenation during surgery is difficult to achieve. Among devices that measure cerebral oxygenation, $\mathrm{SjvO}_{2}$ estimates global cerebral oxygenation and can be used in anesthetized patients during the surgery 8,9 The normal range of $\mathrm{SjvO}_{2}$ is $60-75 \%$ and currently used definition of abnormal $\mathrm{SjvO}_{2}$ is less than $50 \%$ over $5 \mathrm{~min}$. Cerebral oxygenation is determined by the coupling between cerebral blood flow and metabolic rate, and $\mathrm{SjvO}_{2}$ reflects global cerebral blood flow provided that the cerebral metabolic rate remains constant. In the current study, because BIS between the 2 groups were similar and kept between 40 and 60, the cerebral metabolic rate was assumed to be kept constant during surgery without intergroup difference. Cerebral desaturation is known to be closely related to postoperative neurological disorder in cardiac surgery!0,22 Although the time taken to perform Grooved Pegboard Test was significantly prolonged at POD 2 in both groups and some patients showed neurocognitive dysfunction in that test, it is not surprising that none of the patients developed clinically significant neurocognitive dysfunction in the early postoperative period. Our results are quite different from the study of Lee et $\mathrm{al}^{13}$ which reported the incidence of neurocognitive dysfunction as $16 \%$ at postoperative 2 weeks even in 30 non-diabetic patients undergoing OPCAB. Possible explanations for the discrepancy between the results are avoidance of aortic manipulation and relatively wellmaintained $\mathrm{SjvO}_{2}$ in the present study. In our institution, most cases of OPCAB are done by 'no-touch aortic technique' using total arterial grafts. As aortic side-clamping might result in embolism, we had excluded patients who required aortic side-clamping to confine the factors affecting cerebral oxygenation during $\mathrm{OPCAB}$ and postoperative neurocognitive function. In addition, maintaining MAP above $70 \mathrm{mmHg}$ could have played an important role. Usually, most significant hemodynamic changes occur during grafting at the posterior wall of the heart and Trendelenburg position is often required to augment ventricular filling, as well as to optimize surgical exposure. This results in significant increase in CVP as observed in the current study also. Cerebral perfusion pressure is normally determined by MAP and intracranial pressure which is usually well below $15 \mathrm{mmHg}$. Indeed, Trendelenburg position is associated with increase in regional cerebral oxygenation by augmenting cerebral blood flow; 26 however, when the CVP is increased to a level above the intracranial pressure, cerebral perfusion pressure becomes more dependent on MAP and CVP. The mean CVP during RCA grafting were above $13 \mathrm{mmHg}$ in both groups with some patients having a CVP higher than $15 \mathrm{mmHg}$. Under these circumstances, when the MAP is maintained at $60 \mathrm{mmHg}$ or lower, cerebral perfusion pressure would be less than $45 \mathrm{mmHg}$, which could be below the normal limit of cerebral autoregulation in some susceptible patients jeopardizing cerebral oxygenation. In the current study, 3 patients of each group showed cerebral desaturation, and their lowest $\mathrm{SjvO}_{2}$ was $42 \%$ and $44 \%$ in the DM and control group, respectively. This was accompanied by a decrease in $\mathrm{CI}, \mathrm{SvO}_{2}$ and MAP in both groups. However, $\mathrm{CI}$ and $\mathrm{SvO}_{2}$ were near the lower normal limit and MAP was maintained above $70 \mathrm{mmHg}$. As a result, cerebral desaturation rarely developed without intergroup differences. Because only $\mathrm{SjvO}_{2}$ of below $40 \%$ resulted in neurocognitive dysfunction after $\mathrm{OPCAB}$ in a previous study, ${ }^{27}$ maintaining lowest $\mathrm{SjvO}_{2}$ above $40 \%$ during the entire coronary artery anastomosis through maintenance of hemodynamic parameters, especially MAP, could also reduce the chance of developing postoperative neurocognitive dysfunction, as in this study.

$\mathrm{HbA1c}$ in diabetic patients indicates how the blood sugar concentration was controlled for the past 2-3 months and it has been demonstrated that $\mathrm{HbAlc}$ predicts micro- as well as macroangiopathy in diabetic patients, indicating that the primary cause of disturbed cerebrovascular microcirculation is hyperglycemia itself, rather than the severity of $\mathrm{DM}^{2} 2$ Indeed, increased $\mathrm{HbAlc}_{1 c}$ was associated with decrease in $\mathrm{SjvO}_{2}$ during $\mathrm{CPB}$ and with cognitive impairment at 6 months after $\mathrm{CABG}$, confirming the strong correlation between the severity of microangiopathy in diabetic patients and increased $\mathrm{HbAlc}^{29,30}$ As we had included only patients with $\mathrm{HbAlc}$ higher than $7.0 \%$ in the diabetic group, the $\mathrm{HbAlc}$ in the current study was higher than that of previous studies observing cerebral oxygenation in diabetic patients. This further supports that OPCAB exerts favorable effects with regard to cerebral oxygenation in patients with relatively uncontrolled DM and that it may be considered as an alternative surgical technique for patients with DM and at increased risk for postoperative neurological deficits requiring $\mathrm{CABG}$. However, despite the strong correlation between $\mathrm{HbAlc}$ and the presence of angiopathy, ${ }^{28-30}$ whether the results of the present study could also be applied to patients with evident DM complications, such as retinopathy and/or nephropathy, is beyond the scope of this study and remains to be validated.

The limitation of the current study is as follows. This study was designed to focus primarily on the effect of DM on cerebral desaturation measured with $\mathrm{SjvO}_{2}$ during OPCAB and sample size was decided according to that. However, we were unable to draw a correlation between cerebral desaturation and postoperative neurocognitive dysfunction, which was the secondary endpoint of this study, because none of the patients developed neurocognitive dysfunction postoperatively. Therefore, we can only presume that avoiding $\mathrm{CPB}$ could have a beneficial effect in terms of neurologic outcome in diabetic patients based on the well-preserved $\mathrm{SjvO}_{2}$ shown in the current study and the association of cerebral desaturation with neurologic outcome reported in previous studies 10,22 Further studies evaluating the relationship between $\mathrm{SjvO}_{2}$ and postoperative neurocognitive dysfunction in diabetic patients undergoing OPCAB with a sufficient sample size is required.

In conclusion, the cerebral oxygenation measured with $\mathrm{SjvO}_{2}$ in diabetic patients was similar to that of non-diabetic patients and well maintained above the critical level during $\mathrm{OPCAB}$ without resulting in clinically significant postoperative neurocognitive dysfunction.

\section{Acknowledgements}

This work was supported by Korea Research Foundation Grant funded by Korea Government (MOEHRD, Basic Research Promotion Fund) (KRF-2005-003-E00202). 


\section{References}

1. Roach GW, Kanchuger M, Mangano CM, Newman M, Nussmeier $\mathrm{N}$, Wolman R, et al. Adverse cerebral outcomes after coronary bypass surgery: Multicenter Study of Perioperative Ischemia Research Group and the Ischemia Research and Education Foundation Investigators. N Engl J Med 1996; 335: 1857-1863.

2. Newman MF, Kirchner JL, Phillips-Bute B, Gaver V, Grocott H, Jones RH, et al. Longitudinal assessment of neurocognitive function after coronary-artery bypass surgery. $N$ Engl J Med 2001; 344: $395-$ 402.

3. Murkin JM, Martzke JS, Buchan AM, Bentley C, Wong CJ. A randomized study of the influence of perfusion technique and $\mathrm{pH}$ management strategy in 316 patients undergoing coronary artery bypass surgery. II: Neurologic and cognitive outcomes. J Thorac Cardiovasc Surg 1995; 110: 349-362.

4. Nakamura Y, Saitoh S, Takagi S, Ohnishi H, Chiba Y, Kato N, et al. Impact of abnormal glucose tolerance, hypertension and other risk factors on coronary artery disease. Circ J 2007; 71: 20-25.

5. Thourani VH, Weintraub WS, Stein B, Gebhart SS, Craver JM, Jones EL, et al. Influence of diabetes mellitus on early and late outcome after coronary artery bypass grafting. Ann Thorac Surg 1999; 67: $1045-1052$

6. Kadoi Y, Saito S, Yoshikawa D, Goto F, Fujita N, Kunimoto F. Increasing mean arterial blood pressure has no effect on jugular venous oxygen saturation in insulin-dependent patients during tepid cardiopulmonary bypass. Anesth Analg 2002; 95: 266-272.

7. Croughwell N, Lyth M, Quill TJ, Newman M, Greeley WJ, Smith LR, et al. Diabetic patients have abnormal cerebral autoregulation during cardiopulmonary bypass. Circulation 1990; 82: 407-412.

8. Macmillan CS, Andrews PJ. Cerebrovenous oxygen saturation monitoring: Practical considerations and clinical relevance. Intensive Care Med 2000; 26: 1028 - 1036

9. Schell RM, Cole DJ. Cerebral monitoring: Jugular venous oximetry. Anesth Analg 2000; 90: 559-566.

10. Kadoi Y, Saito S, Goto F, Fujita N. Decrease in jugular venous oxygen saturation during normothermic cardiopulmonary bypass predicts short-term postoperative neurologic dysfunction in elderly patients. J Am Coll Cardiol 2001; 38: 1450-1455.

11. Kadoi Y, Saito S, Kawahara F, Goto F, Owada R, Fujita N. Jugular venous bulb oxygen saturation in patients with preexisting diabetes mellitus or stroke during normothermic cardiopulmonary bypass. Anesthesiology 2000; 92: 1324-1329.

12. Miyoshi S, Morita T, Kadoi Y, Goto F. Analysis of the factors related to a decrease in jugular venous oxygen saturation in patients with diabetes mellitus during normothermic cardiopulmonary bypass. Surg Today 2005; 35: 530-534.

13. Lee JD, Lee SJ, Tsushima WT, Yamauchi H, Lau WT, Popper J, et al. Benefits of off-pump bypass on neurologic and clinical morbidity: A prospective randomized trial. Ann Thorac Surg 2003; 76: 18-25.

14. Chernov VI, Efimova NY, Efimova IY, Akhmedov SD, Lishmanov YB. Short-term and long-term cognitive function and cerebral perfusion in off-pump and on-pump coronary artery bypass patients. Eur $J$
Cardiothorac Surg 2006; 29: 74-81.

15. Kim JY, Kwak YL, Oh YJ, Kim SH, Yoo KJ, Hong YW. Changes in jugular bulb oxygen saturation during off-pump coronary artery bypass graft surgery. Acta Anaesthesiol Scand 2005; 49: 956-961.

16. Salomon NW, Page US, Okies JE, Stephens J, Krause AH, Bigelow JC. Diabetes mellitus and coronary artery bypass: Short-term risk and long-term prognosis. J Thorac Cardiovasc Surg 1983; 85: 264271.

17. Tamita K, Katayama M, Takagi T, Akasaka T, Yamamuro A, Kaji S, et al. Impact of newly diagnosed abnormal glucose tolerance on longterm prognosis in patients with acute myocardial infarction. Circ J 2007; 71: 834-841.

18. Dandona P, James IM, Newbury PA, Woollard ML, Beckett AG. Cerebral blood flow in diabetes mellitus: Evidence of abnormal cerebrovascular reactivity. BMJ 1978; 2: 325-326.

19. Maeda H, Matsumoto M, Handa N, Hougaku H, Ogawa S, Itoh T, et al. Reactivity of cerebral blood flow to carbon dioxide in various types of ischemic cerebrovascular disease: Evaluation by the transcranial Doppler method. Stroke 1993; 24: 670-675.

20. Pallas F, Larson DF. Cerebral blood flow in the diabetic patient. Perfusion 1996; 11: 363-370.

21. White RP, Markus HS. Impaired dynamic cerebral autoregulation in carotid artery stenosis. Stroke 1997; 28: 1340-1344.

22. Croughwell ND, Newman MF, Blumenthal JA, White WD, Lewis JB, Frasco PE, et al. Jugular bulb saturation and cognitive dysfunction after cardiopulmonary bypass. Ann Thorac Surg 1994; 58: $1702-1708$.

23. Kilo J, Czerny M, Gorlitzer M, Zimpfer D, Baumer H, Wolner E, et al. Cardiopulmonary bypass affects cognitive brain function after coronary artery bypass grafting. Ann Thorac Surg 2001; 72: 19261932.

24. Hu FB, Stampfer MJ. Is type 2 diabetes mellitus a vascular condition? Arterioscler Thromb Vasc Biol 2003; 23: 1715-1716.

25. Srinivasan AK, Grayson AD, Fabri BM. On-pump versus off-pump coronary artery bypass grafting in diabetic patients: A propensity score analysis. Ann Thorac Surg 2004; 78: 1604-1609.

26. Talpahewa SP, Ascione R, Angelini GD, Lovell T. Cerebral cortical oxygenation changes during OPCAB surgery. Ann Thorac Surg 2003; 76: $1516-1522$.

27. Yoda M, Nonoyama M, Shimakura T. Cerebral perfusion during offpump coronary artery bypass grafting. Surg Today 2004; 34: $501-$ 505.

28. Stratton IM, Adler AI, Neil HA, Matthews DR, Manley SE, Cull CA, et al. Association of glycaemia with macrovascular and microvascular complications of type 2 diabetes (UKPDS 35): Prospective observational study. BMJ 2000; 321: 405-412.

29. Kadoi Y, Saito S, Fujita N, Goto F. Risk factors for cognitive dysfunction after coronary artery bypass graft surgery in patients with type 2 diabetes. J Thorac Cardiovasc Surg 2005; 129: 576-583.

30. Kadoi Y, Saito S, Fumio G, Fujita N. The effect of diabetes on interrelationship between jugular venous oxygen saturation responsiveness to phenylephrine infusion and cerebrovascular carbon dioxide reactivity. Anesth Analg 2004; 99: 325-331. 